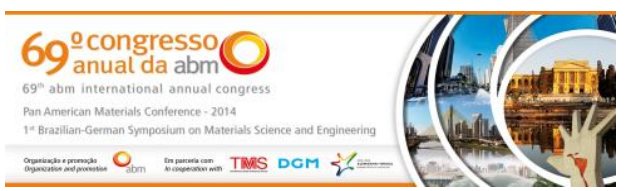

Tema: Mecânica de fratura e integridade estrutural

\title{
ANÁLISE DE ENVELHECIMENTO DO POLIPROPILENO SUBMETIDO À RADIAÇÃO ULTRAVIOLETA*
}

\author{
Ruy José Feijó Alves ${ }^{1}$ \\ Darley Lima² \\ Marcos Daniel Gouveia Filho ${ }^{3}$ \\ Enio Pontes de Deus ${ }^{4}$
}

\section{Resumo}

O policarbonato é um polímero quimicamente neutro, $100 \%$ reciclável, resistente a altas temperaturas, impermeável, durável que oferece uma combinação fantástica das suas propriedades físicas, químicas, mecânicas, térmicas e eléctricas (isolante eléctrico). O policarbonato é um dos plásticos de maior venda e que mostra a maior taxa de crescimento anual no mundo, devido às suas excepcionais propriedades e versatilidade de aplicação e uso. Devido à grande utilização de polímeros nas mais diversas aplicações ao ar livre, surgiu a necessidade de estudar sua resistência às intempéries, não somente por aspectos estéticos, como descoloração ou perda de brilho, mas também por mudanças nas suas propriedades. Os polímeros quando expostos a luz solar na presença de oxigênio são degradados, no entanto as taxas de degradação foto-oxidativa dependem fortemente da natureza química do polímero. Durante o processo de degradação ocorrem mudanças físicas e químicas no polímero que levam à descoloração, fissuramento, perda de brilho e queda de resistência mecânica. Tais fenômenos estão quase sempre associados a processos de cisão de cadeia e, em alguns casos, ocorrem também reticulações. Para se avaliar a estabilidade, ou mesmo avaliar a eficiência de um polímero, é necessário submetêlos a ensaios que simulem as condições às quais ele estaria exposto durante a sua vida útil. Nesse contexto será apresentada uma avaliação sobre a degradação do polipropileno exposto a radiação ultravioleta.

Palavra-chave: Polipropileno; Degradação; Ultravioleta.

\begin{abstract}
ANALYSIS OF AGING OF POLYCARBONATE SUBJECTED TO UV RADIATION
Abstract

Polypropylene is a polymer chemically neutral, $100 \%$ recyclable, high temperature resistant, waterproof, durable, which offers a fantastic combination of physical, chemical, mechanical, thermal and electrical properties (electrical insulator). Polypropylene is one of the biggest selling plastic and shows the highest annual growth rate in the world, due to their exceptional properties and versatility of application and use. Due to the wide use of polymers in various outdoor applications, the need arose to study its weather resistance, not only for aesthetic aspects, such as discoloration or fading, but also by changes in their properties. The polymers when exposed to sunlight in the presence of oxygen are degraded, however the rates of photo-oxidative degradation strongly depend on the chemical nature of the polymer. During the process of degradation of the physical and chemical changes occur that lead to polymer discoloration, cracking, loss of gloss and decrease of mechanical strength. Such phenomena are almost always associated with processes of chain scission and in some cases also occur crosslinks. To assess the stability or evaluate the efficiency of a polymer is necessary to subject them to tests simulating the conditions to which he was exposed during its lifetime. In that contest an assessment of the degradation of polypropylene exposed to ultraviolet radiation will be presented.
\end{abstract}

Keywords: Polypropylene; degradation; Ultraviolet.

1 Graduando, Engenharia Metalúrgica e de Materiais, Laboratório de Mecânica da Fratura e Fadiga, Universidade Federal do Ceará, Fortaleza, CE, Brasil.

2 Mestrando, Engenharia e Ciência dos Materiais, Laboratório de Mecânica da Fratura e de Materiais, Universidade Federal do Ceará, Fortaleza, CE, Brasil.

3 Graduando, Engenharia Metalúrgica e de Materiais, Laboratório de Mecânica da Fratura e Fadiga, Universidade Federal do Ceará, Fortaleza, CE, Brasil.

4 Doutor, Professor, Laboratório de Mecânica da Fratura e Fadiga, Universidade Federal do Ceará, CE, Brasil

* Contribuição técnica ao 69 Congresso Anual da ABM - Internacional e ao 14ํㅡㄹ ENEMET - Encontro Nacional de Estudantes de Engenharia Metalúrgica, de Materiais e de Minas, 21 a 25 de julho de 2014, São Paulo, SP, Brasil 


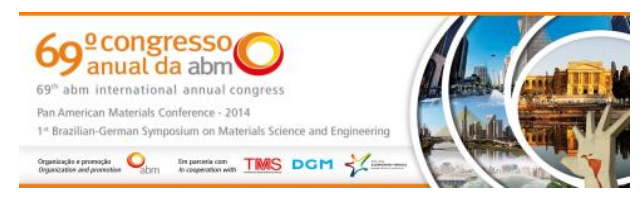

\section{INTRODUÇÃO}

Polipropileno (PP) é um polímero, mais precisamente um termoplástico, de forma molecular $\left(\mathrm{C}_{3} \mathrm{H}_{6}\right)$ x. Termoplástico é um plástico (polímero artificial) que, a uma dada temperatura, apresenta alta viscosidade podendo ser conformado e moldado. Antes de atingir o estado fundido passam por uma transição vítrea ( $A$ temperatura de transição vítrea é a temperatura acima da qual existe "mobilidade" das macromoléculas ou a temperatura abaixo da qual, as macromoléculas estão "congeladas" e sofrem fratura de modo da frágil. Quanto mais baixa a temperatura de transição vítrea mais dúctil é o polímero [1]. Por ser um material de baixo custo, de fácil moldagem, de alta resistência à fratura por flexão ou fadiga, de elevada resistência química e de fácil coloração, vem se tornando cada vez mais utilizado dentro da indústria como um todo, sendo empregado em diversas áreas: Embalagens flexíveis; Fibras; Cadeiras plásticas; Embalagens e recipientes para alimentos, remédios e produtos químicos; Material hospitalar esterilizável e, também, para tampas de higrômetros. Por ser um dos plásticos de maior venda, e que mostra a maior taxa de crescimento anual do mundo, surgiu a necessidade de estudar sua resistência às intempéries, não somente por aspectos estéticos, como descoloração ou perda de brilho, mas também por mudanças nas suas propriedades químicas e mecânicas, com a intenção de descobrir os limites suportados pelo material e expandir as áreas em que pode se atuar o polipropileno.

Os polímeros quando expostos a luz solar na presença de oxigênio são a degradados, no entanto as taxas de degradação foto-oxidativa dependem fortemente da natureza química do polímero. Durante o processo de degradação ocorrem mudanças físicas e químicas no polímero que levam à descoloração, fissuramento, perda de brilho e queda de resistência mecânica. Tais fenômenos estão quase sempre associados a processos de cisão de cadeia e, em alguns casos, ocorrem também reticulações. Para se avaliar a estabilidade, ou mesmo avaliar a eficiência de um polímero é necessário submetê-los a ensaios que simulem as condições às quais ele estaria exposto durante a sua vida útil. Nesse contesto será apresentado uma avaliação sobre a degradação do polipropileno exposto à radiação ultravioleta.

\section{MÉTODOS E MATERIAIS}

As amostras de polipropileno foram expostas ao envelhecimento acelerado por radiação ultravioleta e condensação de vapor d'água. Para caracterizar o envelhecimento do material foram realizados os ensaios de Análise Termogravimétrica (TGA) [1] e Infravermelho [2] com transformada de Fourier (FTIR).

\subsection{Envelhecimento Acelerado}

O envelhecimento acelerado das amostras de PEMD foi feito seguindo a norma ASTM G154 com programação adotada referente ao ciclo 2 que consiste em 4 horas de exposição à radiação ultravioleta a $60^{\circ} \mathrm{C}$ seguido de 4 horas de condensação de vapor d'água a $50^{\circ} \mathrm{C}$. O ensaio foi realizado através do sistema de envelhecimento acelerado para não- metálicos do fabricante COMEXIM.

* Contribuição técnica ao 69ํCongresso Anual da ABM - Internacional e ao 14 ENEMET - Encontro Nacional de Estudantes de Engenharia Metalúrgica, de Materiais e de Minas, 21 a 25 de julho de 2014, São Paulo, SP, Brasil 


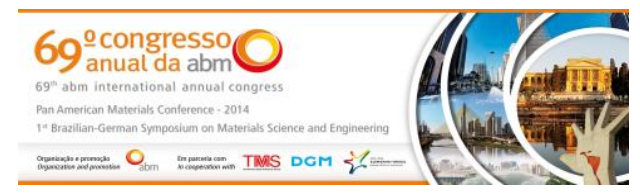

As amostras foram estudadas no tempo de envelhecimento acelerado de $0,600 \mathrm{e}$ 1200 horas.

\subsection{Análise Termograviméterica}

A Análise Termogravimétrica [1-2] é definida como um processo contínuo que envolve a medida da variação de massa de uma amostra em função da temperatura (varredura de temperatura), ou do tempo a uma temperatura constante (modo isotérmico). Esta técnica possibilita conhecer a faixa de temperatura em que a amostra adquire uma composição química fixa, a temperatura em que se decompõe e o andamento das reações de desidratação, oxidação, combustão, decomposição. As análises termogravimétricas podem ter três modos: TG isotérmica, TG quasiisotérmica, e TG dinâmica. Ao sofrer degradação, o resultado da análise é de que o polímero perde massa, sob forma de produtos voláteis, e essa perda é registrada pela curva no gráfico.

\subsection{Espectrometria Infravermelha com Transformada De Fourier (FTIR)}

O espectro infravermelho [2] de um composto químico é considerado uma de suas propriedades físico-químicas mais características e, por conta disto, a espectroscopia na região do infravermelho tem extensa aplicação na identificação de compostos. A técnica de espectroscopia Infravermelha com transformada de Fourier (FTIR) de um material consiste em registrar as frequências características devidas à interação de uma onda electromagnética com as ligações químicas constitutivas do material. A FTIR se baseia no fato de que as ligações químicas das substâncias possuem frequências de vibração específicas, as quais correspondem a níveis de energia da molécula (chamados de níveis vibracionais). A análise vibracional de polímeros fornece informações sobre três importantes características estruturais do material: A composição química; A estrutura configuracional e conformacional; e as Forças interatômicas associadas às ligações de valência ou interações intermoleculares.

\section{RESULTADOS E DISCUSSÃO}

\subsection{Análise dos Gráficos de TGA}

Após todas as amostras terem sido submetidas às análises termogravimétricas [1] e de espectrometria de infravermelho [2], todos os dados revelados estão expostos nas figuras 1, 2 e 3. As informações restantes estão presentes na tabela 1.

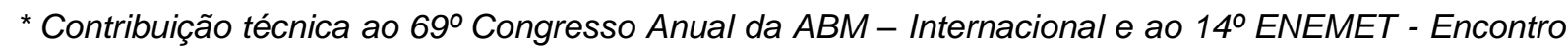
Nacional de Estudantes de Engenharia Metalúrgica, de Materiais e de Minas, 21 a 25 de julho de 2014, São Paulo, SP, Brasil 

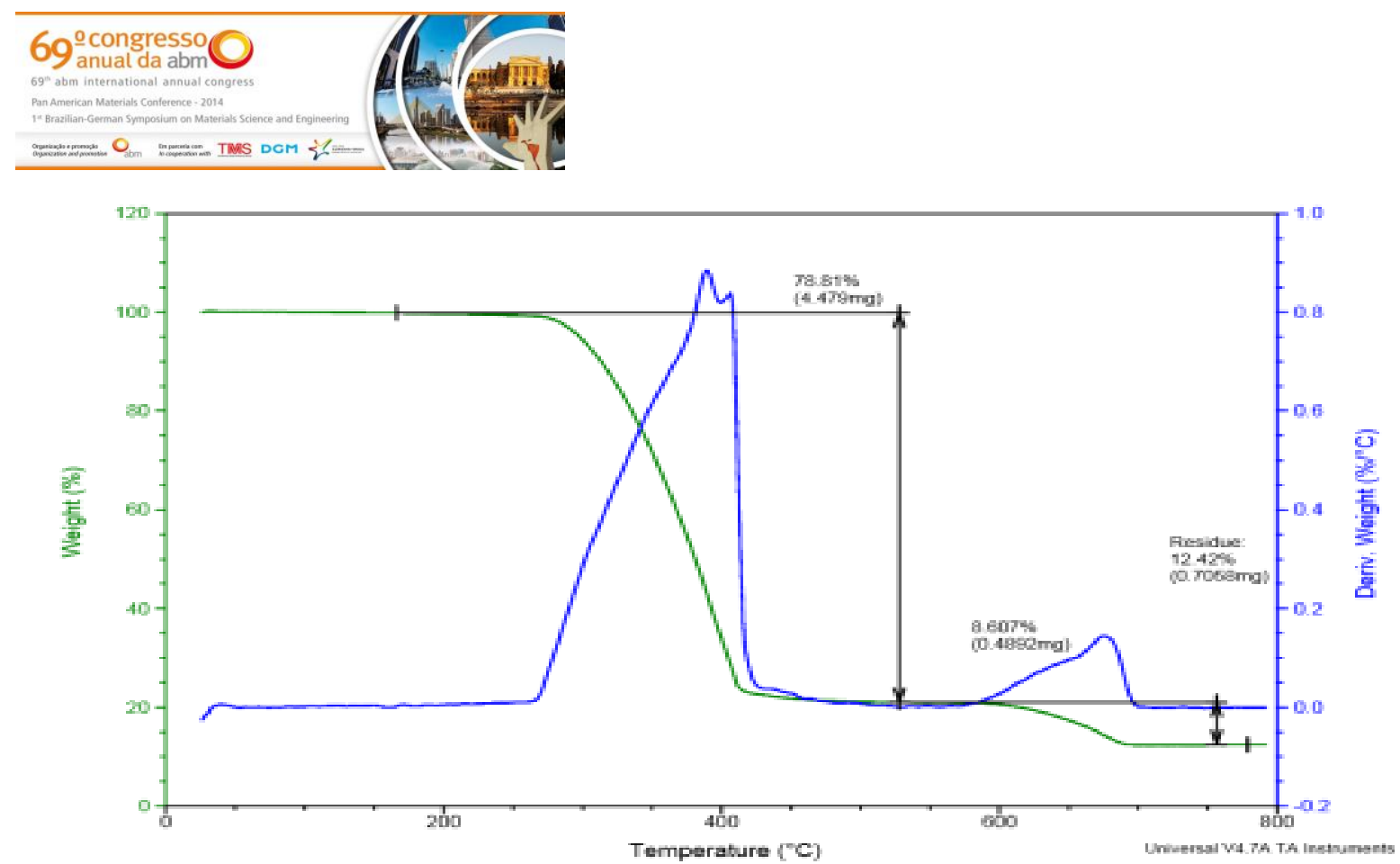

Figura 1 - PP envelhecido zero hora.

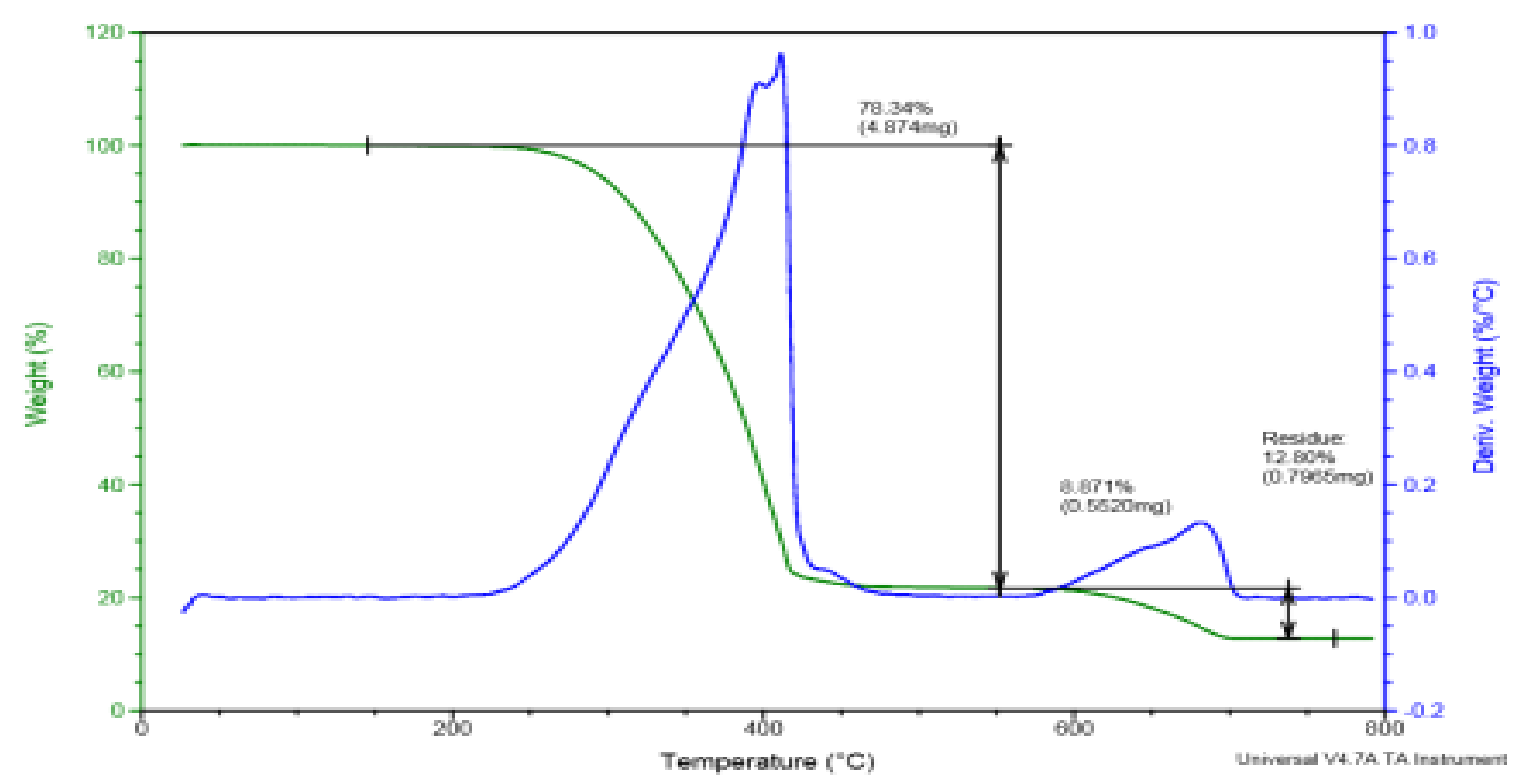

Figura 2 - PP envelhecido 600 horas.

* Contribuição técnica ao 69 Congresso Anual da ABM - Internacional e ao 14ํㅡㄹ ENEMET - Encontro Nacional de Estudantes de Engenharia Metalúrgica, de Materiais e de Minas, 21 a 25 de julho de 2014, São Paulo, SP, Brasil 

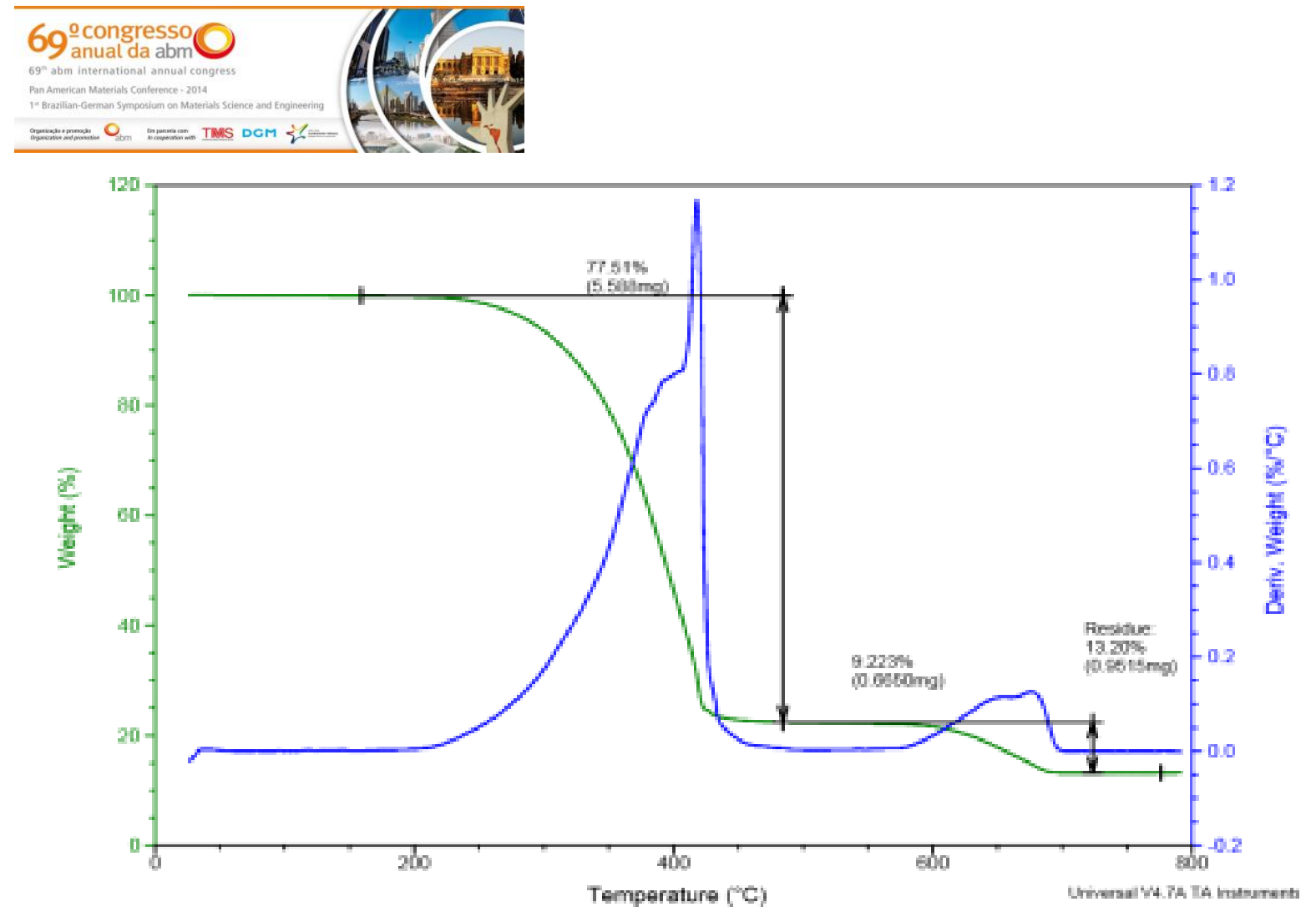

Figura 3 - PP envelhecido 1200 horas.

Tabela 1:

\begin{tabular}{|c|c|c|c|}
\hline Envelhecimento & $\begin{array}{c}\text { Temp. início de } \\
\text { degradação }\end{array}$ & Temp. crítica & $\begin{array}{c}\text { Temp. final } \\
\text { degradação }\end{array}$ \\
\hline 0 Hora & $263^{\circ} \mathrm{C}$ & $420^{\circ} \mathrm{C}$ & $691^{\circ} \mathrm{C}$ \\
\hline 600 Horas & $241^{\circ} \mathrm{C}$ & $430^{\circ} \mathrm{C}$ & $695^{\circ} \mathrm{C}$ \\
\hline 1200 Horas & $231^{\circ} \mathrm{C}$ & $430^{\circ} \mathrm{C}$ & $693^{\circ} \mathrm{C}$ \\
\hline
\end{tabular}

Informações que se obtém da curva de TGA são: porcentagem de massa perdida em cada um dos processos, massa de resíduos não voláteis e velocidade de perda de massa. É importante lembrar, embora pareça óbvio, que a curva de TGA só evidenciará as reações de degradação térmica ou termo-oxidativa (no caso de usar atmosfera oxidante) que provocarem variação de massa. Os resultados das análises termogravimétricas revelam que o material que não sofreu envelhecimento (zero hora) tem uma maior estabilidade térmica, tendo a maior temperatura de início de degradação. As amostras envelhecidas a 600 e 1200 horas tiveram uma temperatura mais baixa para início de degradação, $241^{\circ} \mathrm{C}$ e $231^{\circ} \mathrm{C}$ respectivamente, mas percebe-se que a temperatura crítica e a temperatura de final de degradação, das três amostras, são muito próximas. Durante o envelhecimento foi formado uma camada de óxido sobre cada amostra. $\mathrm{Na}$ análise termogravimétrica foi revelado o quanto de resíduo que foi gerado em cada material, foi visto que a camada de resíduo (camada de óxido) formada no PP de zero hora foi de 0,70968 mg $(12,42 \%)$, no PP de 600 horas foi de $0,7955 \mathrm{mg}(12,80 \%)$ e no PP de 1200 horas foi de 0,9615 $\mathrm{mg}(13,20 \%)$.Com essa análise foi percebido que quanto mais envelhecido for um material, maior será sua perda de massa e a sua taxa de oxidação.

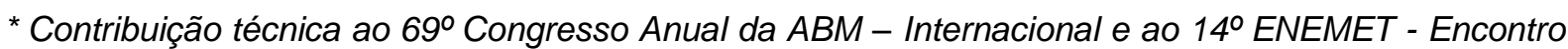
Nacional de Estudantes de Engenharia Metalúrgica, de Materiais e de Minas, 21 a 25 de julho de 2014, São Paulo, SP, Brasil 


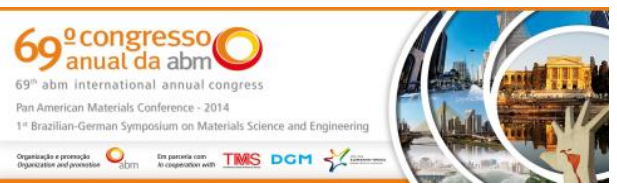

\subsection{Análise dos Gráficos de Espectrometria de Infravermelho}

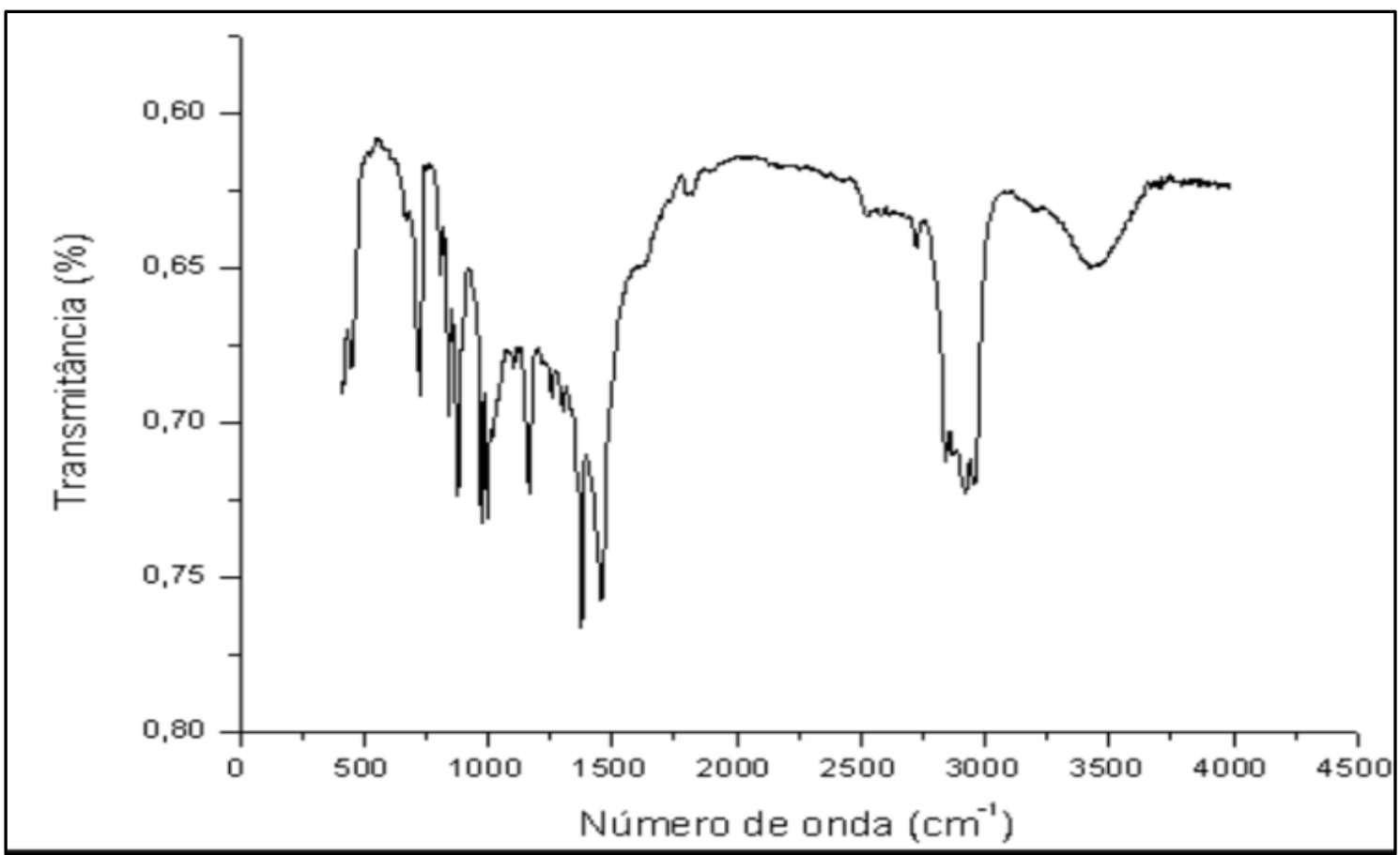

Figura 4 - PP envelhecido 0 hora.

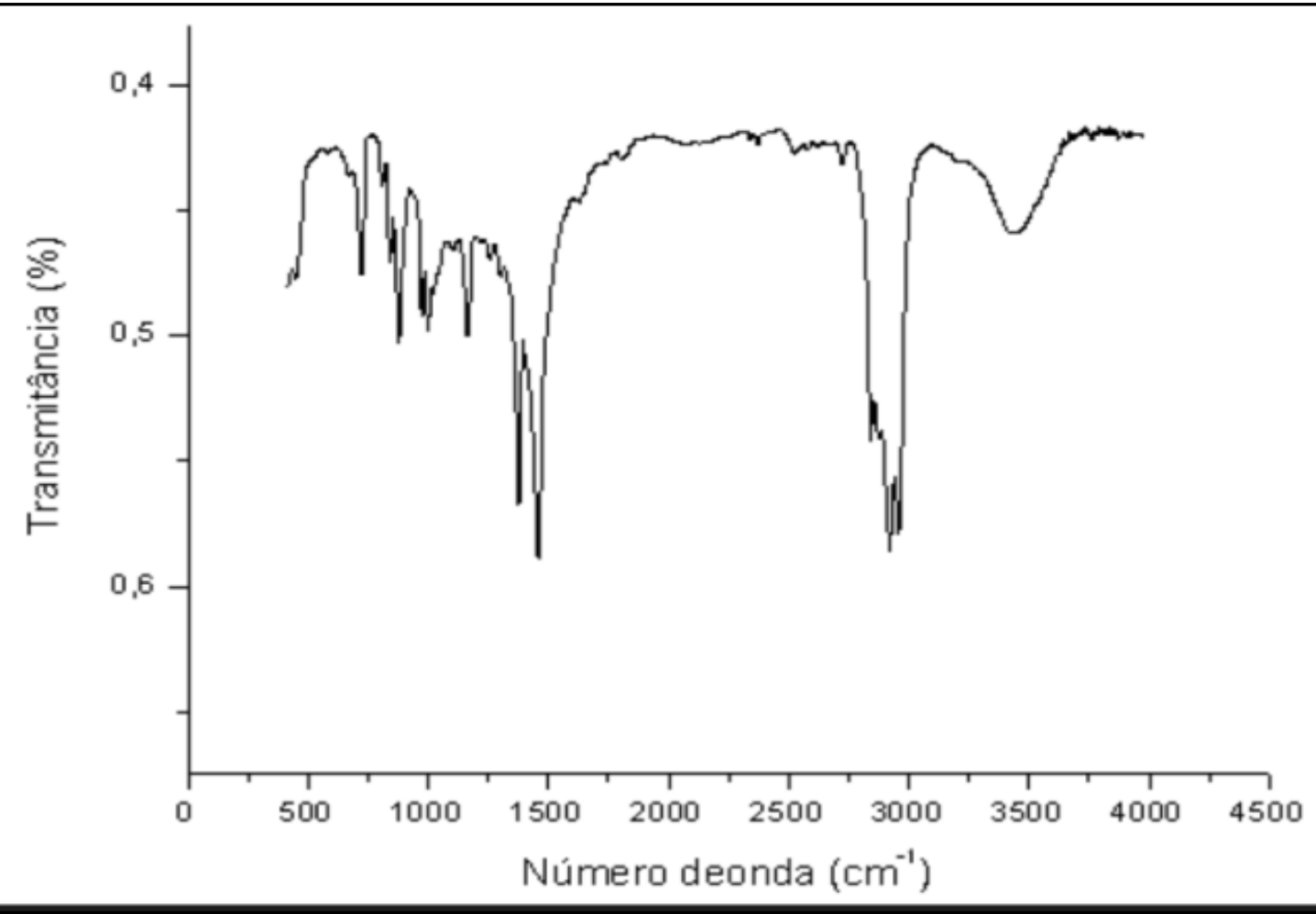

Figura 5 - PP envelhecido 600 horas.

* Contribuição técnica ao 69 Congresso Anual da ABM - Internacional e ao 14ํㅡㄹ ENEMET - Encontro Nacional de Estudantes de Engenharia Metalúrgica, de Materiais e de Minas, 21 a 25 de julho de 2014, São Paulo, SP, Brasil 


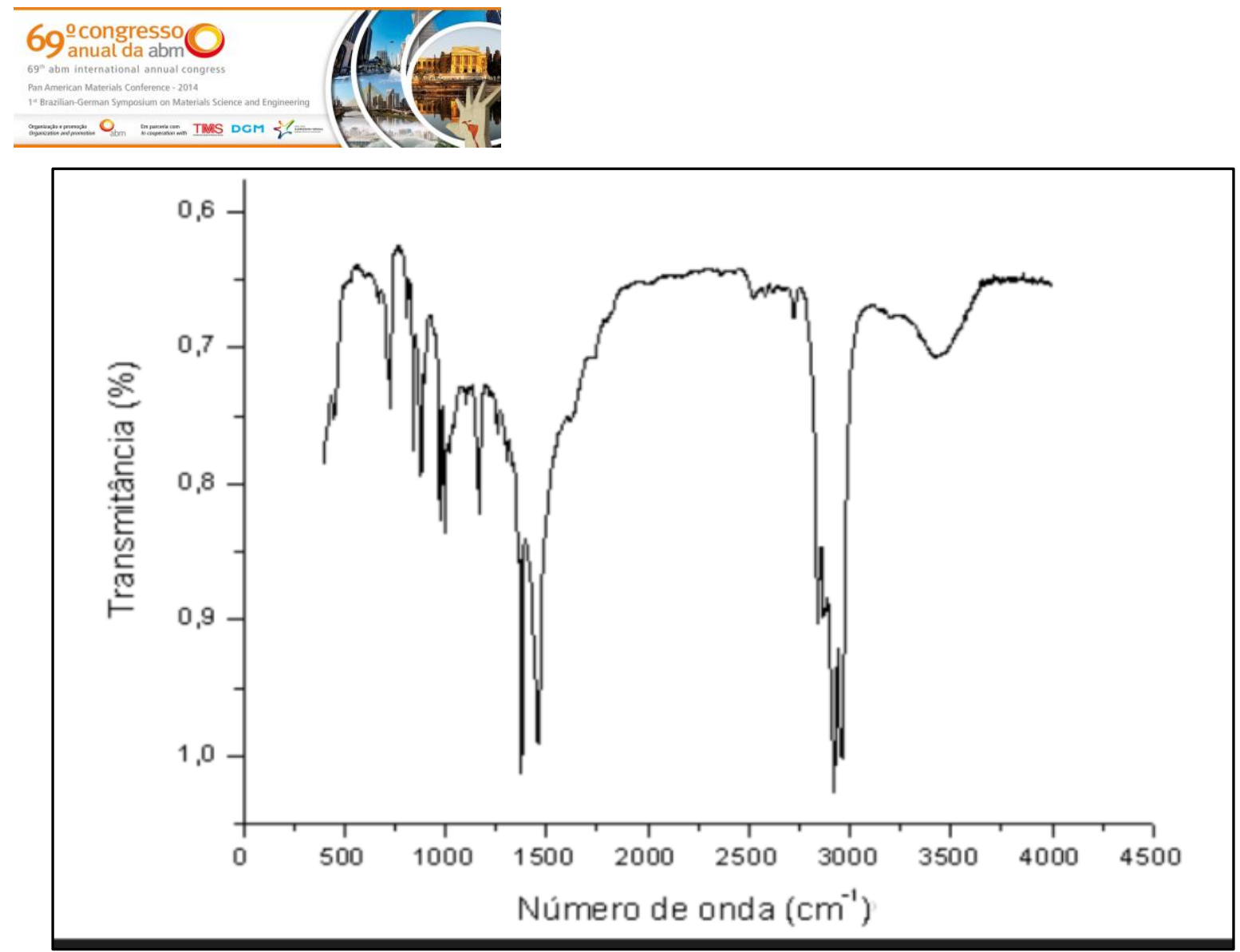

Figura 6 - PP envelhecido 1200 horas.

Para fins de análise, um espectro no infravermelho [2] pode ser dividido nas regiões de 4000 a $1300 \mathrm{~cm}^{-1}$ (região 1), de 1300 a $900 \mathrm{~cm}^{-1}$ (região 2) e de 900 a $500 \mathrm{~m} \mathrm{~cm}^{-1}$ (região 3). A região 1 é a região dos grupos funcionais, geralmente nessa região aparecem poucas bandas de absorção, as quais se referem aos estiramentos de ligações dos principais grupos funcionais, como $\circ[\mathrm{OH}]$ e $\circ[\mathrm{C}=\mathrm{O}]$. A região 3 geralmente apresenta bandas fortes nos casos de compostos aromáticos, heteroaromáticos e alquenos, essas bandas são devidas a deformação angular fora do plano de ligações [=C-H]. A região 2 é a mais complexa, sendo muitas bandas originadas de modos vibracionais acoplados e vibrações referentes ao esqueleto carbônico das moléculas. Essa região é denominada impressão digital, uma vez que ela serve para confirmar a identidade de determinado composto, pois mesmo isômeros que apresentam espectros idênticos nas outras regiões apresentarão diferenças nessa faixa de número de ondas. Dentre as absorções mais importantes, estão aquelas devidas ao estiramento de ligação [ $\mathrm{C}-\mathrm{O}]$ de álcoois, fenóis, éteres e ésteres.

Analisado os gráficos percebe-se que na região entre 2800 a $3300 \mathrm{~cm}^{-1}$, onde encontra-se a presença de ligações [C - H], há uma atenuação do vale, que indica o aumento desse tipo de ligação através dos ciclos de envelhecimento. Na região entre 1400 a $1600 \mathrm{~cm}^{-1}$, onde encontra-se as ligações [C=O], também há uma atenuação no vale no transcorrer da degradação do PP.

\section{CONCLUSÃo}

Foi percebido, por meio da análise termogravimétrica [3] e pela espectrometria de infravermelho [2], que o Polipropileno sofre degradação devido a radiação ultravioleta e condensação por vapor dágua, ocasionando uma formação de uma camada de óxidos superficiais que afetam diretamente suas propriedades de

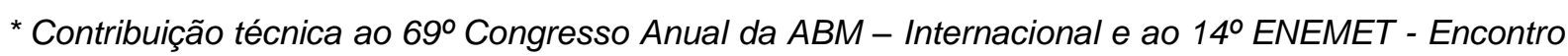
Nacional de Estudantes de Engenharia Metalúrgica, de Materiais e de Minas, 21 a 25 de julho de 2014, São Paulo, SP, Brasil 
estabilidade térmica. Não foram estudadas as propriedades mecânicas do Polipropileno, mas podem ser estudadas em outros projetos, como sugestão.

\section{Agradecimentos}

Agradeço a Professora Selma Elaine, do laboratório de polímeros (labpol), por disponibilizar toda a infraestrutura para que pudessem ser realizados os testes de análises térmicas do Polipropileno.

\section{REFERÊNCIAS}

1 Canevarolo J, Voic S. Ciência dos polímeros,um texto básico para técnologos e engenheiros, $2^{a}$ edição.

2 Barbosa, LCA. Espectrometria no infravermelho na caracterização de compostos orgânicos, Editora UFV.

3 Lucas EF, Soaes BG, Monteiro E. Caracterização de polímeros, Determinação de peso molecular e análise térmica, Editora e-papers. 